\title{
THE
}

$12-15-2016$

\section{Peer Influence: Mechanisms and Motivations}

\author{
Barbara J. Costello \\ University of Rhode Island, costello@uri.edu \\ Christine Zozula \\ University of Rhode Island, zozula@uri.edu
}

Follow this and additional works at: https://digitalcommons.uri.edu/soc_facpubs
The University of Rhode Island Faculty have made this article openly available. Please let us know how Open Access to this research benefits you.

This is a pre-publication author manuscript of the final, published article.

Terms of Use

This article is made available under the terms and conditions applicable towards Open Access Policy Articles, as set forth in our Terms of Use.

\section{Citation/Publisher Attribution}

Costello, Barbara J., and Christine Zozula, C. "Peer influence: Mechanisms and motivations." Deviant Behavior, vol. 39, no. 1, 2018, pp. 94-110. http://dx.doi.org.uri.idm.oclc.org/10.1080/ 01639625.2016 .1260387

Available at: http://dx.doi.org.uri.idm.oclc.org/10.1080/01639625.2016.1260387

This Article is brought to you for free and open access by the Sociology \& Anthropology at DigitalCommons@URI. It has been accepted for inclusion in Sociology \& Anthropology Faculty Publications by an authorized administrator of DigitalCommons@URI.For more information, please contact digitalcommons-group@uri.edu. 
Peer Influence: Mechanisms and Motivations

\begin{abstract}
Social science research on peer influence has focused on learning and reinforcement processes as potential explanations for the correlation between peer behavior and the individual's behavior. These explanations assume that social ties can have either positive or negative effects on human behavior, depending on the nature of the groups to which the individual belongs. This view has been contested by those working in the control theory tradition in criminology, who argue that all social ties promote conformity. To shed new light on this debate, we ask a question that has not been addressed in previous research - why do youths try to influence their friends' behavior? Our analysis of written accounts of peer influence toward both positive and negative behaviors reveals clear differences in motives for peer influence toward positive, prosocial behavior and negative, deviant behavior. Influence toward deviant behavior is much more likely to be motivated by selfish concerns, and influence toward prosocial behavior is more likely to be motivated by altruistic concerns. These findings are consistent with the view that crime and deviance is asocial behavior, and not the result of strong social ties to others.
\end{abstract}




\section{Peer Influence: Mechanisms and Motivations}

There is a long history of research in criminology that documents the relationship between individuals' deviant behavior and that of their peers. The earliest sociological theories of crime were essentially designed to explain the group nature of delinquency (Shaw, 1931; Shaw and McKay, 1942) and the fact that delinquent youth tend to have delinquent friends (Sutherland, 1947). These empirical relationships are virtually undisputed in the literature. Nevertheless, scholars debate why these correlations exist, and decades of research have failed to produce any definitive conclusions about causal processes that may link friends' delinquency to the individual's delinquency. As one leading scholar in the field stated in the conclusion of his book on the subject, many explanations of peer influence on deviance "border on the mystical" (Warr, 2002: 139).

We argue that one reason for the lack of progress in understanding peer influence processes is the overreliance on quantitative data and the misplaced faith in quantitative methods to provide new insights into peer influence processes. Existing large data sets that have been frequently used to try to reveal the nature of group influence on deviance simply do not contain measures that allow researchers to distinguish one mechanism of influence from another. Another tendency in the literature that has slowed our progress in understanding peer influence is researchers' apparent assumption that any causal effect of peers on deviance is the result of socialization or learning processes, even in the absence of any direct evidence of learning or norm transference. In a sense, learning theories "own” the peer effect in criminology (Costello, 2010). 
In this research, we begin to move past these barriers to furthering our understanding of peer influence processes by simply asking respondents to report on specific instances of peer influence they have been involved in, both toward and away from deviant behavior. Building on the work of Costello and Hope (2016), we look not only at the mechanisms of influence reported by our respondents, but also at respondents' motivations for trying to influence their peers. Thus, our research begins to shed light on both what youths are doing in interaction with their friends, and why they say they're doing it. Our results have important implications for theoretical debates on the nature of peer influence.

\section{Theoretical Explanations of the Peer "Effect"}

The idea that our associates can influence our behavior is an old one. As early as 300 B.C., the Greek dramatist Thais noted that "evil companionships corrupt good morals" (Burt, 1925: 123). Even Cesare Lombroso, best known for his argument that crime is the result of atavism, stated that a "depraved environment, which counsels or even insists on wrongdoing, and the bad example of parents or relatives" are "sinister" influences on children (Lombroso Ferrero, 1911: 144.

Some of the earliest sociological explanations of crime centered on explaining the delinquency/peer delinquency connection. Shaw and McKay (1942) developed their social disorganization theory to explain persistently high rates of delinquency in certain Chicago neighborhoods. They argued that low levels of informal social control in socially disorganized neighborhoods allowed unsupervised groups of boys to engage in delinquent behavior. 
Eventually, delinquent and criminal subcultures formed in these neighborhoods, and these groups perpetuated criminal traditions over time. In this way, Shaw and McKay's theory included elements of both social structure and culture in their explanation of crime (Kornhauser, 1978).

Other theories, such as Sutherland's (1947) differential association theory and Burgess and Akers's (1966) differential association-reinforcement theory, focused largely on cultural processes to explain the relationship between delinquency and delinquent peers. These "socialization" theories hold that norms, values, or "definitions" conducive to crime are learned through interaction with others (Sutherland, 1947), and that learning occurs through the process of operant conditioning (Akers, 1998). For learning theories, then, deviance has social causes, as it is the result of our ties to others.

The first major challenge to learning theories came in Hirschi's (1969) presentation of social control theory. Hirschi argued that differential association or cultural deviance theories begin from an erroneous view of human nature as prosocial, a nature that requires a push to crime if it is to occur. Hirschi took the Hobbesian view that human nature is asocial, and that we are inherently motivated by self-interest. In this view, then, crime is nonproblematic, and conformity is what requires explanation. Hirschi's explanation of delinquency drew on Durkheim's idea that conformity to social rules is the product of social integration, or that "we are moral beings to the extent that we are social beings" (cited in Hirschi, 1969: 18). For Hirschi, then, the cause of deviance is not social, but rather asocial, and our ties to others promote conformity.

Hirschi explained the relationship between delinquent friends and delinquency by 
drawing on the earlier work of the Gluecks, who claimed that the relationship was spurious, the result of self-selection processes. As the Gluecks put it, "birds of a feather flock together," (Glueck and Glueck, 1950: 164), and youths who have similar tendencies toward deviance tend to come together to engage in mutually enjoyable activities. Hirschi retained this view in his later work developing self-control theory (Gottfredson and Hirschi, 1990). In this view, crime is the result of low self-control, or the tendency to impulsively pursue immediate gratification and a weak ability to work toward long-term goals. Low self-control also leads to membership in groups with others similarly lacking in self-control. For Gottfredson and Hirschi, crime is fun, thrilling, and provides quick and easy benefits. All of these may be enhanced by the presence of others, but membership in deviant groups does not cause these behaviors. Thus, both Hirschi's (1969) theory and Gottfredson and Hirschi's (1990) theory can be viewed as "selection" theories, in sharp contrast to socialization theories.

The socialization versus selection debate dominated the literature on peer influence for years, both in criminology and in the wider sociological literature (Kandel, 1978). One consequence of the focus on socialization and learning theories versus self-selection and control theories was a lack of exploration into alternative explanations of the peer effect. It wasn't until the mid-1990's that an alternative to these two views was formally proposed and tested. This alternative is a simple opportunity effect, or the idea that deviant friends have a causal effect on deviance, not through teaching deviant norms and values, but by presenting opportunities for deviance that would not exist otherwise (Osgood et al., 1996). This view is derived from routine activities theory (Cohen and Felson, 1979), which explains crime with reference to situational variables that make crime easier or more rewarding (Osgood et al., 1996). 


\section{Research on Alternative Explanations of the Peer "Effect"}

Not surprisingly, there is some evidence supportive of all of these alternative explanations of the correlation between delinquency and peer delinquency, in addition to a number of additional possibilities that have received less attention in the criminological literature (see Warr, 2002, for a review). Tests of differential association and social learning theory consistently show that attitudes toward crime are correlated with criminal behavior, and that friends' behavioral similarity tends to increase over time (Simons-Morton and Chen, 2006), suggesting a socialization or learning effect. On the other hand, a number of studies have found that self-selection accounts for a substantial portion of the relationship between delinquency and friends' delinquency, supportive of control theory (Chapple, 2005; Haynie and Osgood, 2005; Kandel, 1978; Matsueda and Anderson, 1998; Mercken et al., 2012; Rebellon, 2012). There is also evidence supportive of a simple opportunity effect, in that unstructured socializing with friends in the absence of adults or other likely agents of social control is associated with greater rates of deviance (Osgood et al, 1996; Osgood and Anderson, 2004).

However, there has been little research that allows us to adjudicate between these competing explanations. Although there is evidence pointing away from attitude transference as an explanation of peer influence (Warr, 2002; Warr and Stafford, 1991), researchers often assume that any causal relationship between deviance and peer deviance is evidence of learning processes (Costello, 2010). For example, McGloin's (2009) review of the literature on the peer effect notes that there is "impressive" evidence in support of the socialization perspective, even while she acknowledges that most studies measure only exposure to delinquent peers and not the 
actual learning process. Similarly, Matsueda and Anderson (1998) conclude that the relationship between delinquency and peer delinquency that remains after self-selection is controlled provides evidence for learning theories and against control theories, even though there were no measures of attitudes toward crime in their analysis. Haynie (2001) found that network density is associated with greater behavioral similarity among members of both deviant and conforming groups. She concluded that these findings were more supportive of learning theories than control theories, but there were no measures of attitudes toward deviance or the learning process in her analyses. Thus, these researchers fail to adequately consider the possibility that a casual effect of peer delinquency on delinquency can be anything other than a socialization or learning effect. However, as Warr notes, the correlation between delinquent friends and delinquency that remains after self-selection is taken into account "says nothing about the process or mechanism of influence that gave rise to it, and the number of possibilities is large" (2002: 134).

This gap in the literature has recently been addressed by Costello and Hope (2016). Their study of peer influence processes among a convenience sample of students at two universities uncovered a wide range peer influence techniques toward both deviant and conforming behavior. Using student accounts of specific incidents of peer influence, Costello and Hope found that the most commonly used method of peer influence toward deviant behavior reported in their sample involved students simply inviting their friends to participate, which occurred in about $36 \%$ of total incident classifications ( $\mathrm{N}=189)$. Despite the lack of attention to the concept peer pressure in the criminological literature, Costello and Hope's (2016) analysis revealed that it was fairly common in their sample, with $23 \%$ of total incident classifications falling under the category of "coercive" methods of influence, including ridicule. Other common methods of influence 
included convincing others to engage in deviance by minimizing the potential negative consequences of the behavior, convincing others to engage in deviant or dangerous stunts for the entertainment of onlookers, and respondents reporting that they engaged in a deviant behavior because they thought others in a group who were engaging in that behavior would like them better if they joined in.

Costello and Hope (2016) also argued that friends can have a positive influence on each other's behavior, either by attempting to prevent deviance or by encouraging positive behaviors, such as those related to academic success or healthy lifestyles. Working from a control theory perspective (Hirschi, 1969; Gottfredson and Hirschi, 1990; Laub and Sampson, 2003; Sampson and Laub, 1993), Costello and Hope (2016) argue that criminology has largely ignored the possibility that friends can have a direct, positive influence on each other's behavior, despite the fact that a correlation between deviance and friends' deviance is necessarily also a correlation between conformity and friends' conformity (Costello, 2010). Viewed this way, this empirical relationship provides just as much evidence for social control theory as it does for learning theories, particularly given our lack of understanding of mechanisms of peer influence. If we don't know why deviance and peer deviance are correlated, the correlation can hardly be taken as evidence for one theory over another.

Costello and Hope's (2016) analysis of positive peer influence revealed a great deal of positive peer pressure among their respondents, and it is likely that this positive influence has prevented hundreds of deviant acts in their small sample alone. The three most common methods of positive influence were analogous to the common methods of negative influence in their sample. Coercive methods were most common, comprising $36 \%$ of total classifications of 
incidents. Many of these involved peers trying to keep each other from driving after drinking or drug use, for example by forcibly taking someone's car keys away. Other common methods of positive influence included maximizing the negative consequences of deviance or maximizing positive consequences of prosocial behaviors, and making simple offers or invitations.

The picture that emerged from these data was more supportive of the situational opportunity perspective (Osgood et al, 1996; Osgood and Anderson, 2004) and control theories of crime than of learning or cultural explanations. Costello and Hope (2016) note that there were very few references by any of their respondents to norms or values in the influence attempts, and efforts to convince reluctant peers that they should engage in a behavior were much more likely to invoke the unlikely chance of getting caught than any moral qualities of a behavior. It is important to note that this study specifically focused on situational influence rather than friends' influence that might occur over time, so this study could not address normative influence that might occur over time in the course of a friendship. However, based on the patterns exhibited in this sample of students, norms and values regarding deviant behavior seemed largely irrelevant in peer influence attempts.

Although the Costello and Hope (2016) research revealed a number of mechanisms of peer influence, the researchers were left with a question of great theoretical importance - why do peers try to influence each other's behavior, either toward or away from deviance? Costello and Hope (2016) noted that some attempts at influence toward deviance seemed motivated by selfish concerns, particularly incidents that were classified as being for the entertainment or benefit of onlookers. For example, one of their respondents recounted this story of an incident that occurred during a party in the woods: 
Later in the night when they decided to let this kid drive, he drove his car down a wrong path down a hill deeper into the woods. Luckily he had a four wheel drive explorer, but the kids in the car were enjoying his mishaps. They continued to egg him on as he tried to reverse his car, breaking headlights and taillights on trees and stumps. They made it out of the woods and home without any legal issues, but what sorts of friends treat each other in this manner?

A similar incident occurred during a night of drinking at a bar:

One girl kept drinking till she was dangerously drunk, yet people continued to buy her drinks because they found her actions amusing. Another girl even recorded the night and posted it to Youtube.

These incidents portray an image of peer influence that is very different from the normative influence learning theories portray. For learning theories, groups socialize their members into a variety of behaviors because group norms define those behaviors as acceptable or laudable. Sutherland (1947) argued that society is characterized by normative conflict, and that criminal behavior is normal learned behavior. When people have more contact with those espousing prodeviant "definitions," those norms and values are learned. Akers (1998) further specified that learning is achieved through operant conditioning, through which certain groups reinforce deviant behavior and definitions among their members. As noted earlier, then, for differential association and learning theories, crime is social behavior. Some groups are “organized for criminal behavior" and some are "organized against criminal behavior" (Sutherland, Cressey, and Luckenbill, 1992:90), but crime is always the result of social processes, since it is learned through contact with others who have favorable definitions of criminal behavior. 
In contrast, control theory views crime as asocial in that it does not need to be learned, and in fact is likely to result when socialization processes fail or when the individual is unattached to others or to society in general. For social control theory (Hirschi, 1969), a weak social bond, including our attachments to others, frees individuals to commit crime. For selfcontrol theory (Gottfredson and Hirschi, 1990), inadequate socialization in early childhood prevents children from developing self-control. One outcome of low self-control is a tendency to have weak or unstable personal relationships, because maintaining relationships with others requires effort and at least some degree of self-sacrifice. As Gottfredson and Hirschi put it, crime is "antigroup" behavior that often involves the victimization of members of one's own social group (1990:156), and "the exhibition of these tendencies undermines harmonious group relations and the ability to achieve collective ends" (1990:96).

Opportunity-based theories don't focus on individual differences in the likelihood of committing crime, and instead explain variation in crime rates with reference to situational characteristics that make crime more or less likely to occur. However, opportunity and routine activities theories are grounded in rational choice theories, which clearly start with the same assumptions about human nature as control theories. Our natural tendencies are to maximize pleasure and minimize pain, and crime often allows us to achieve desires with little effort. Osgood et al. (1996:637) also note that routine activities theory "explicitly eschews explanation in terms of values and normative standards," further differentiating it from value-based explanations such as those offered by learning theories. Thus, opportunity and routine activities theories also view crime as asocially motivated, and not as the result of social learning processes.

These competing views of the nature of criminal and deviant behavior lead to very 
different predictions about motivations for social influence toward such behavior. For control and opportunity theories, and consistent with some of Costello and Hope's (2016) findings, social influence toward deviance or crime is likely to be asocially motivated. To the extent that individuals influence each other toward deviance, then, control and opportunity theories would predict that the motives behind the influence attempts are likely to be selfish, or to the benefit of the individual doing the influencing. In contrast, for cultural deviance or learning theories, we would expect that motives for influence toward deviance are either prosocial or neutral, since it is fundamental to learning theories that crime is the result of attitudes that support the behavior. If crime is good or acceptable, then trying to get someone to commit crime should be motivated by concern for the other's welfare or, at minimum, a lack of self-interest.

Control theories would also predict a clear difference in motives for influencing others toward deviance or away from deviance and toward prosocial behaviors. Because control theories assume a single moral order, they hold that even those who violate the law realize that what they are doing is wrong, even though there is variation in the strength of people's belief in the law (Hirschi, 1969). Thus, for control theories, people recognize right and wrong and the potential harm that can result from engaging in deviance, and people who have bonds to others should be likely to try to steer their behavior away from crime and toward positive behaviors. Because learning theories hold that both crime and conformity are motivated by belief that the behaviors are at least acceptable, there should be little difference in motives for influencing friends toward or away from crime.

Although some of Costello and Hope's findings are consistent with the control theory perspective on influence toward deviance, they did not explicitly ask their respondents to report 
on their motives for attempting peer influence. As a result, they were unable to draw any general conclusions about motives for influence. Our primary goal in this study, then, is to address this gap in our understanding of peer influence. Why do friends or acquaintances try to get their friends to engage in criminal or deviant behavior? Are their motives similar to or different from motives for trying to get peers to refrain from deviance, or to engage in prosocial, positive behaviors like studying more or eating more healthfully? And what do motives for peer influence tell us about the nature of crime, deviance, and peer influence processes?

\section{Methods}

Our data were collected from a convenience sample of students in two introductory sociology classes in spring 2014. As an extra credit assignment, we asked students to describe a time when they attempted to influence someone to do something "positive" and a time they influenced someone to do something negative (i.e. something "illegal, deviant, risky, or otherwise not a good idea"). On average, student papers were approximately two double spaced pages. We use these narratives as data.

Our sample consisted of 44 men, 75 women and 12 unidentified $(\mathrm{N}=131)$. Aside from respondent's gender, the data were anonymous. ${ }^{1}$ Not all students provided information for both positive and negative influence attempts -- some only provided information for either one type of

\footnotetext{
${ }^{1}$ Students who completed the extra credit were asked to submit a consent form with their name on it, at the same time that they submitted their narratives which did not have any identifying information included. Students who submitted consent forms were given extra credit. The number of consent forms matched the number of submitted papers. Two students, a man and a woman, submitted papers that did not answer the questions asked, so those papers were excluded.
} 
influence or the other, and others provided descriptions of two positive influence attempts or two negative influence attempts. In total, our sample contains 123 positive influence attempts and 111 negative influence attempts. The median grade of students who completed the extra credit was within one point of the median grade for all of students, so we are confident that these assignments reflect the "average student" in these classes.

We used an open coding scheme (Charmaz, 2006). Coding began by reviewing the papers and identifying variables. Next, we developed specific categories of each variable. To ensure intercoder reliability, each author coded 30 of the same papers. We met to confirm that our coding agreed, and for cases that were coded differently, we discussed to clarify categories. After this meeting, we divided the papers in half and coded independently. During this stage of the coding process, we continued to refine categories, deleted redundant categories, and discussed any papers that raised questions. Frequency tables, cross tabulations, and correlations were created using STATA 11.2.

This sample and method are well-suited for an exploratory study. While a convenience sample of college students is not generalizable to other, more deviant groups, it is an appropriate sample for a descriptive study that first broaches the issue of motivation. Further, there is no lack of deviant behavior among college students. Binge drinking among college students has been the focus of a great deal of research (Wechsler et al., 2002), and President Obama recently created a task force to address concerns about sexual assault among college and university students. One study found that the prevalence of crime victimization among college students at about $25 \%$ in one academic year (Fisher, Sloan, Cullen, and Lu, 1998).

In addition, a sample of college students is in some ways ideal for a study of peer 
influence processes. Many students are away from home and the direct supervision of their parents for the first time, and they are in a social environment comprised almost entirely of same-age peers. Clearly, there is a great deal of opportunity for experimentation with new behaviors, and a great deal of opportunity for peer influence to occur in this population.

Our method, asking students to write a descriptive account, offers a number of benefits and, from what we can tell, is a novel method for criminological research. ${ }^{2}$ It provides many of the benefits of in-depth interviewing while requiring much less time and money. It allows us to get respondents' descriptions of deviant events in their own words, something scholars have noted is lacking in criminological research (Laub and Sampson, 2003). Because our research is exploratory, it was important for us not to limit our respondents' accounts by imposing response categories on them as is typical in survey research. From a practical standpoint, the study did not cost any money beyond the paper required for the assignment instructions and consent forms. The population is convenient, particularly for researchers in academia. Because college students are more literate than other populations, asking respondents to write their own accounts poses few technical challenges. Although we left the age at influence attempt open-ended, we imagine this technique could be used for longitudinal studies, for instance, if one asked respondents to provide narratives at different points in their lives.

There are some drawbacks to this method however. Missing data are a problem. As any reader who teaches college students knows, students do not always follow directions, so some narratives excluded information that we specifically requested, and we did not have the

\footnotetext{
2 Though it seems to be used for research on sexual health and education (See Allen and Brooks 2012; Allen, Kaestle, and Goldberg 2010).
} 
advantage of following up as we would in an interview. Next, there may be some debate about how "free" these narratives are. Our directions (see Appendix A) requested specific information. This could mean that there are other variables that matter that are not captured by these accounts because we did not specifically ask for that information. We also have no way to confirm the veracity of accounts. This method is an account from one person's perspective, and does not capture the perspectives of others involved in the incidents described. Finally, despite ensured anonymity, respondents may have felt reluctant to recount more serious deviant and criminal behavior, and may have selectively provided accounts that involved more minor offending or influence attempts that cast the respondent in a more positive light.

We collected data on the respondent's gender, the gender of the person being influenced, the strength/type of relationship, the duration of the influence attempt, the method of influence, the time of influence (whether the student was in college, high school, or before high school), and whether or not the attempt was successful. Additionally, our initial reading of student accounts revealed a number of instances in which students expressed regret for negative influence attempts, and often our respondents noted that the person they influenced positively thanked them later. Thus, we recorded data on these variables for all students' accounts as well.

In this paper, the key variable of interest is the motivation for influencing someone to do something positive and/or something negative. To measure motivations behind influence attempts, we asked students to "explain why you did what you did. Why did you try to influence your friend or friends to do that behavior?" 


\section{Results}

Types of Behavior and Methods of Influence

Although the primary purpose of this research is to reveal the motives behind peer influence attempts, to provide context we briefly describe the types of behaviors and methods of influence commonly reported by our respondents. Table 1 shows the behaviors that respondents described attempting to influence someone to engage in. For negative influence attempts, respondents most often tried to convince others to drink alcohol $(26 \%)^{3}$, engage in bad academic behavior (16\%), and smoke marijuana (12\%). There are two kinds of positive influence attempts: influencing someone to do something positive, or influencing someone away from illegal, risky, or otherwise "bad" behavior. Many respondents described attempting to prevent someone from drunk driving (17\%), influencing someone to stay in college or pursue a college education (11\%), and influencing someone to improve his/her fitness or health (11\%).

\section{TABLE 1 ABOUT HERE}

Respondents also varied on methods they use to attempt to influence someone (See Table 2). The most common methods for negative influence attempts included minimizing consequences $(23 \%)$, persistent offers $(17 \%)$, coercive techniques $(13 \%)$, and simple suggestions (13\%). The following excerpts illustrate these common methods.

Minimizing legal, academic, or parental consequences: "I told her that her parents were asleep and they wouldn't wake up or hear us leaving."

Persistent offers: "After minutes had passed and she realized that I would keep persisting until she took the beer from my hands, she hesitantly said yes."

\footnotetext{
${ }^{3}$ Percentages throughout this paper are rounded to the nearest whole number.
} 
Coercive techniques ${ }^{4}$ : “As much as the other kids didn't want any part of it at first, after an hour of sufficiently calling them 'pussies' and making sure they knew they had no pride, they finally agreed."

Simple suggestions: "[I] simply offered [my friend] some of my drink that I had already been drinking."

The most common methods of influence for positive influence attempts were simple offers/suggesting practical solutions (21\%) and emphasizing costs and/or benefits associated with the behavior (19\%). Respondents also influenced people to engage in positive behavior or desist from negative behavior using coercive techniques (11\%) or talking to the person (9\%) Please refer to the following excerpts for typical descriptions of each of these methods:

Simple offers/Practical Solutions: A respondent prevented his father from driving drunk with this method. "There was no fight, I didn't want to embarrass him or anything so I just asked if he minded if I drove home."

Emphasizing Costs \&/or Benefits: A respondent said to her friends, "Come on guys, we all know that we should not be at a party right now. Think about your GPAs and how they will go down if you do not do well on your final exams. Anyway, if we study more now, we will not have to study as much at the end of the semester and we can go to more parties."

Coercive techniques: "For weeks, other friends of mine and myself would swat cigarettes out of their mouths, throw away packs of cigarettes, and make fun of them for smoking."

Talking: A friend prevented a fight because "[he] jumped in and explained the whole situation."

\section{TABLE 2 ABOUT HERE}

\footnotetext{
${ }^{4}$ Persistent offers could arguably also be considered coercive. We considered them separately. Perhaps the simplest way to state the difference is through an example: a respondent offering someone alcohol multiple times is a persistent offer, but a respondent offering someone alcohol and telling him/her to "stop being a baby and let's drink" is coercion.
} 
Motivations for Negative Influence Attempts

We now turn to the question of why our respondents were motivated to influence others' behaviors. There are 111 negative influence attempts in our sample. Ten respondents reported negative influence attempts, but did not report motive, and some narratives contained multiple motives for one influence attempt. Our data include 101 negative influence attempts with motive and 157 motives. Table 3 provides an overview of the reported motivations for influencing someone towards negative behavior.

\section{TABLE 3 ABOUT HERE}

The most common motivations for negative influence attempts included the writer's own personal amusement or benefit (18\%), the respondent's desire to have someone be deviant with $\mathrm{him} / \mathrm{her}(11 \%)$, the respondent's desire to spend time with someone $(11 \%),{ }^{5}$ and the respondent's belief that the target of influence would enjoy the negative behavior (11\%).

Writer's Own Benefit or Amusement. Respondents often described encouraging others to do something negative because it would benefit or amuse the writer him/herself. The two following excerpts illustrate motivating others for one's amusement:

“...when Brick gets drunk, he's extremely funny to interact with. Whenever Brick gets blacked out he dances and sprints around the house saying very silly things that just don't make sense. I guess Lauren and me wanted to ensure that happened, which it did." -woman, convinced an acquaintance to drink to excess

“...there was no real reason to do what I did. The majority of it was just that I knew that

\footnotetext{
5 "Wants someone to be deviant with them" is different from "wants to spend time with person." Again, an example: The former would be motivating someone to sneak out of the house and go to a party because the respondent didn't want to go alone; the latter would be motivating someone to sneak out and attend a party because they want to see their friend.
} 
I could easily manipulate him and have him do something for my enjoyment. I believe it was all just for enjoyment."

-man, convinced a friend to suction his face with a plunger, later revealed that the plunger was recently used to unclog a toilet

Other incidents show manipulation for the writer's own benefit, other than for simple

amusement, as shown in the example below:

"My reasoning behind getting Jess drunk was so she would relax and have a good time. But I only wanted her to have a good time so she wouldn't ask me to drive her home. My act of peer-pressure was entirely selfish. I knew that if Jess was drunk enough, I would be able to stay at the party and get wasted."

-woman, convinced friend to stay at a party when her friend wanted to leave

Wants Someone to be Deviant with Him/Her. Another common motivation for negative influence attempts is the respondent's desire to have someone be deviant with him/her (11\%). It seems that having a partner in crime can be a way to assuage guilt or to make potential consequences less harsh, as the two following examples illustrate:

"I felt that if I had a friend join in on my negative behavior, it would make me feel better about myself because I wasn't doing it alone."

-woman, convinced friend to sneak out and go to party

"I did this with selfish intentions in mind and put my own desired before what was best for my roommate and I. I did this because I felt bad about wanting to skip class and I knew that had I skipped alone I would have felt a lot guiltier about the situation than I would if I had someone committing the devious act with me."

-woman, convinced friend to skip class

However, in other cases, respondents wanted others to be deviant with them because it would be more fun than being deviant alone. The following account illustrates this motivation:

"I didn't want to do it alone and I knew it would be more fun if we were all drunk." -woman, convinced friends to sneak alcohol into dance

Desire to Spend Time with Someone. Another common motivation for influencing a 
friend to engage in negative behavior was the desire to spend time with someone $(11 \%) .{ }^{6}$ While some respondents clearly made a pointed effort due to the desire to spend time with someone, for others the respondent assumed apriori that their friend would engage in deviance with them, just by virtue of their friendship. The following excerpts describe each type of this response:

"I didn't want him to get in trouble but I just really wanted to spend the time with him... I obviously love spending time with him so I wanted him to call off his prior commitment and come hang out with my friends and me. I only get to see him on the weekends when I'm at school so I try to get as much time with him as possible."

- woman, convinced boyfriend to call in sick to work and attend a party

"The two of us always go out together so I wanted her to come with me because we always have a lot of fun together."

-woman, convinced friend to go to a party during midterm week. (The friend missed her exam the next day).

Enjoy Negative Behavior. Many respondents said that they influenced someone to do something negative because they thought the person would enjoy the negative behavior (11\% of reported motives). These reported motivations were commonly associated with attempting to influence someone to consume alcohol or smoke marijuana. ${ }^{7}$ :

"I influenced him to do this because he told me he wished he was drunk and he wanted to have more fun and I knew if he was drunk he would loosen up and have a better time. I was really just trying to help him have a better time since the rest of us were so much worse than him and he was miserable because we didn't have a care and he was too tense."

-man, convinced friend to binge drink

\footnotetext{
6 "Wants someone to be deviant with them" is different from "wants to spend time with person." Again, an example: The former would be motivating someone to sneak out of the house and go to a party because the respondent didn't want to go alone and the latter would be motivating someone to sneak out and attend a party because they want to see their friend.

${ }^{7}$ Of the 17 cases that reported they were motivated by a desire to spend time with someone, 3 were related to alcohol and 5 were related to marijuana. Of those who reported that they influenced someone to do something because they wanted to have fun, almost half (8/17) said that they influenced friend to drink alcohol, and 3/17 motivated friend to smoke marijuana.
} 
In many instances, respondents felt that making a negative influence attempt was part of their understanding of themselves as a "good friend."

"As her friend, I felt that it was my place to get her trashed before she went to the rave... I decided to do this because I wanted my friend to have a good time and enjoy herself." - man, convinced friend to get drunk before going to a rave by herself

“...I was determined to get her to have just a little bit [of alcohol] so she could enjoy herself.... This was a bad move on my part, at first I thought I was being a good friend. But after that first drink -- she became so much happier, and it made me happy." -woman, convinced a designated driver to have a drink (The friend later received a DUI)

While many of these motivations were connected with drug or alcohol use, some were unrelated:

"I am not to [sic] sure why I tried to influence my friend to doing something that might possible harm her, maybe because I just wanted her company, or maybe I felt that if she and everyone else who tanned made me feel like it isn't harmful to my body because tons of people do it. Most of all she can't lecture me anymore how bad it is to tan because she would be a hypocrite."

-woman, convinced friend to go to a tanning salon, despite her friend's reservations about health risks associated with tanning.

\section{Motivations for Positive Influence}

Our sample includes 169 motives across 123 positive influence attempts. As Table 4 shows, the most common motivations are: concern for someone's physical well-being or health, empathy for the person they influenced, not wanting the other person to be unhappy or afraid, and the respondent's sense of morality.

\section{Table 4 ABOUT HERE}

Health or Physical Consequences. Students often reported that they encouraged positive behavior or discouraged negative behavior due to concern with the health or physical 
consequences of the other person's actions. This response commonly involved convincing someone to exercise or eat healthier, refrain from drinking or smoking, or refrain from driving drunk. Typical responses resembled the following:

"Lung cancer is something that hits home for me, watching my friends potentially raise their risk of getting cancer scared me after I lost loved ones to the disease."

- man, convinced friend to quit smoking cigarettes.

"I did what I did because I would never let someone who had been drinking and was not capable of driving get behind the wheel and put herself and everyone else in danger." -woman, convinced someone she had just met to refrain from driving drunk

However, not all of these influence attempts were solely motivated by concern for another person; some respondents also mentioned concerns about guilt if one did not intervene. Below is a representative excerpt:

"I knew how serious eating disorders were from my health class and how they take a serious toll not on a humans [sic] physical being but their mental being as well. If I didn't try to influence my friend to start eating again, I would feel extremely guilty if anything serious happened to her and would carry a huge burden on my shoulders."

-woman, tried to convince friend to eat

Help Someone Succeed or Avoid Negative Consequences. About 11\% of reported motives

away from negative behavior were categorized as a desire to help someone succeed or avoid negative parental, legal, or academic consequences. The two quotes below illustrate this motive.

"The reason I cared so much about my friends going to that party is that I knew they needed to bring their grades up in some of their classes."

-woman, convinced friends to continue studying rather than going to a party

"... I truly felt he was making a "big mistake" and I didn't think that doing drugs was going to help him, whatsoever on his exams. Also, it was going to be his first time doing the drug and assuming he were to do it alone, he would be in big trouble if he were to get a bad reaction from it or even worst [sic] get caught with it."

-man, convinced friend to refrain from smoking marijuana 
Empathy. The other most common reported motive in our data is empathy for the person involved. The two excerpts below illustrate empathetic motivations.

“...I understood where she was coming from. Years ago I fell off my horse and broke my wrist...I wanted her to know she wasn't alone and that she can overcome any fear." -woman, convinced acquaintance to continue horse riding after a breaking her leg in a riding accident

"I tried to influence Tori to not talk to Mike because I know the situation she's been in and I know it takes a toll on you.... I tried to influence Tori because I cared about her well being."

-woman, tried to convince friend to break up with a physically and sexually abusive boyfriend

A Note on Missing, Unclear and "Other" Motivations. Our data contains some missing motivations, unclear motivations, or motivations that were uncommon. Some respondents did not write about why they attempted to influence someone else, and those data are coded as missing. Others provided unclear accounts about their motives. For example, one respondent described persuading his friend not to fight someone because he "later found out that the kid my friend intended to fight was carrying a knife on him and was supposedly ready to use it." The respondent's writing was generally unclear, and the motive he stated occurs after the influence attempt. Some motivations were unique and did not appear more than once in our data. These motives were coded as "other." For instance, a student convinced a friend to stay in college after a difficult first semester because:

"I knew how excited she was to go to the school. Everything came very easy to her in high school so I knew she had to learn what it meant to work towards something that is difficult and that if she gave up now she will have no problem with giving up in the future."

We collapsed other and unclear motivations into one category because in both cases respondents 
reported a motive, making them distinct from respondents who did not report a motive.

Types of Motivations. To determine whether motivations for peer influence differed by type of influence, we next categorized motivations as selfish, altruistic, or neither for both positive and negative influence attempts. We conceptualized selfish motives as those focused on the respondents' own wishes or desires, and altruistic motives as those focused primarily on others. Most motives clearly fit into one of these categories. For example, motivating someone to do something negative because one is bored is clearly selfish, while motivating someone to do something positive because one doesn't want someone else to be unhappy is clearly altruistic. For those motives that were less clearly selfish or altruistic, we reviewed each paper and decided on a case by case basis. (Tables 3 and 4 indicate which motives were selfish, altruistic, neither, or varied.)

Table 5 shows the variation in selfish and altruistic motivations across influence attempts. Of 162 motivations reported for positive influence, $83 \%$ of reported motives were altruistic, $12 \%$ of motives were selfish and $6 \%$ were neutral. In contrast, of the 143 reported motives for negative influence, $36 \%$ were altruistic, $53 \%$ were selfish, and $10 \%$ were neutral. ${ }^{8}$ Since many of our respondents reported multiple motivations for one influence attempt, we also looked at the combination of reported motives for each influence attempt. Each influence attempt could be motivated by selfish, altruistic, or neutral reasons. We then separated each influence attempt's combination of motives into purely selfish, purely altruistic, neither, both selfish and altruistic, altruistic and neither, selfish and neither. ${ }^{9}$ Table 6 documents that distribution. We find that $74 \%$

\footnotetext{
${ }^{8}$ Some of the "unclear" motives remained unclear upon coding for selfish/altruistic/neutral.

${ }^{9}$ A purely selfish motivation may be illustrated by a respondent's narrative about driving his father's van without his father's permission. The respondent broke a mirror on the van, and then bribed a friend to help him steal a mirror
} 
of positive influence attempts had purely altruistic motivations as compared to $23 \%$ of negative influence attempts. In contrast, only $4 \%$ of positive influence attempts were motivated by purely selfish reasons as compared to $45 \%$ of negative influence attempts.

Generally speaking, motivations to influence someone towards pro-social behavior or away from negative behavior are altruistic, and close to half of the reported motivations towards negative behavior are purely selfish. When we consider the motivations towards negative behavior as "selfish plus" we find that $61 \%$ of the respondents' accounts included at least one selfish motivation. It is possible that many respondents attempted to minimize or justify their behavior by including additional neutral or altruistic motivations for influencing someone to engage in negative behavior. However, even a conservative interpretation of the data shows that

to replace the broken one. The student wrote: "I was afraid of how my father would react if he found out my friends and I damaged the company van without even having our licenses... I guess I thought that I could avoid the consequences by committing a crime."

A respondent's description of her and her friends intervening to stop a friend from dropping out of school illustrates a purely altruistic influence attempt. The writer describes that she and her friends offered their support, "so that our friend did not throw away her future and drop out of school," and personally because "I really wanted to make sure that things started to work out for her."

Other influence attempts had neither a selfish nor altruistic motivation. For instance, a female respondent tried to influence her friend to sneak into a movie with unused tickets because, "the tickets were already paid for, and I didn't want to waste two perfectly good tickets."

In some cases an incident was coded as both selfishly and altruistically motivated. One respondent reported trying ot get her roommates to eat more healthfully and to go to the gym regularly. She wrote, “... I, myself did not want to gain the freshmen fifteen and I knew if I was living with people who did not have any motivation to eat healthy or work out then I would fall into the similar path and not do that. I guess you could say I did it for my own personally gain, but I helped out two of my friends in the process." 
influence toward deviance is much more likely to be motivated by selfish concerns, and influence toward conformity is much more likely to be motivated by concern for others.

\section{Discussion and Conclusions}

Our data clearly show a difference in motives for influencing someone toward deviance or away from deviance or toward positive behaviors. This finding is more consistent with control and opportunity theories than with learning theories. For control and opportunity theories, crime is motivated by self-interest, it can be fun, and the presence of others can make crime and deviance easier or more fun than it would be alone. The idea that peer influence toward deviance is also motivated by self-interest is thus very consistent with these perspectives. If the primary motive for engaging in criminal or deviant behavior oneself is to maximize pleasure and minimize pain, it follows that motives for influencing others to engage in deviance are also to maximize pleasure and minimize pain. If drinking with friends is more fun than drinking alone, naturally the self-interested individual might try to convince friends to join him or her in that behavior. If someone wants to steal something but thinks an accomplice would make it easier, then convincing a friend to help is a rational course of action. If people realize that a behavior they want to engage in is harmful or wrong, it might make it psychologically easier for them to engage in the behavior if their friends do it with them, as in the case of our respondent who convinced her friend to go to the tanning salon with her. In that case, an added benefit was to stop her friend from "lecturing her" about the behavior. In short, for both control theories and opportunity theories, it makes sense that people who desire to engage in criminal or deviant 
behaviors will be likely to encourage friends to join them in these behaviors. Friends can enhance the pleasure of those activities or minimize the potential pains involved in the behaviors or their consequences.

Although neither control nor opportunity theories of deviance have attempted to explain positive peer influence, it is consistent with these perspectives that the motives for positive influence would differ from those toward negative influence. Because control theories explicitly assume a single moral order, they hold that everyone recognizes the potential negative consequences of crime and deviant behavior. Thus, people who have strong bonds to others do not want to see them engage in behaviors that are potentially harmful to them. Whereas crime is asocially motivated, positive peer influence is socially motivated, according to control theories. Although rational choice and opportunity theories of crime do not discuss emotional bonds to others given their focus on macro-level causes of crime, it is consistent with these theories that bonds to others would be likely to motivate positive peer influence. A bond to others give us something to lose through their criminal or deviant behavior. Concern for the other becomes a source of pleasure or pain for the individual.

In contrast, for differential association, social learning, or other cultural explanations of crime and deviance, there is no clear reason why motives for positive or negative influence should vary. If both deviant and conforming behavior are defined as positive or at least as acceptable, then there should be no difference in motivation to influence a friend or peer toward either behavior. Attempts at deviant influence should be just as likely as attempts at positive influence to be motivated by altruistic concerns.

Our findings are clearly more supportive of control and opportunity theories than they are 
of learning theories. There are many reasons to question the notion that deviant behavior is caused by learned definitions of the behavior as good or acceptable. Attitudes and behavior are often in conflict, and research on peer influence has shown that friends' behavior is more predictive of the individual's behavior than the individual's own attitudes are (Warr and Stafford, 1991). Despite existing literature that calls into question learning theories' explanation of the peer effect, these explanations persist in the literature. Our findings cast further doubt on the veracity of these explanations, and suggest that it is time for researchers to explore alternative approaches to explaining the peer effect.

Our findings also suggest some interesting avenues for future research on altruistic behavior. Current research on altruism tends to focus on group-level issues like the free rider problem in achieving collective goods (Simpson and Willer, 2015). Our research suggests that the study of altruistic behavior might benefit by incorporating the study of crime, in our view a fundamentally selfish behavior.

Finally, and perhaps most importantly, we have a great deal to learn about the processes of both positive and negative peer influence. Our study is obviously exploratory, to the best of our knowledge the first to examine motivations for positive and negative peer influence. It will be useful to investigate the extent to which our findings can be replicated with larger populations that are more representative of the youth population as a whole, and with more deviant populations. Learning more about the types of people who are likely to intervene to prevent deviance, and the situations in which this typically happens, can lead to better attempts to reduce deviance and crime among young people. Learning more about why peers try to influence each other toward deviance might also help us learn how to reduce those forms of influence or to 
teach young people how to resist them. 


\section{Appendix}

\section{$\underline{\text { Abridged Assignment Instructions }}$}

"Describe in as much detail as you can a time when you tried to influence another person or group's behavior in a "negative" direction, that is, toward a behavior that is illegal, deviant, risky, or otherwise not a good idea."

"Describe in as much detail as you can a time when you tried to influence another person or group's behavior in a "positive" direction, that is, trying to get someone to not do something negative as described above, trying to get someone to stop doing something they were doing that was negative, or trying to get someone to do something that was a good thing to do." 


\section{References}

Akers, Ronald L. 1998. Social Learning and Social Structure: A General Theory of Crime and Deviance. New Brunswick, NJ: Transaction Publishers.

Allen, Katherine R., and Jada E. Brooks. 2012. "At the Intersection of Sexuality, Spirituality, and Gender: Young Adults' Perceptions of Religious Beliefs in the Context of Sexuality Education." American Journal of Sexuality Education. 7(4): 285-308.

Allen, Katherine R., Christine E. Kaestle, and Abbie E. Goldberg. 2010. "More than Just a Punctuation Mark: How Boys and Young Men Learn about Menstruation." Journal of Family Issues. 32(2): 129-156.

Burgess, Robert L. and Ronald L. Akers. 1966. "A Differential Association-Reinforcement Theory of Criminal Behavior.” Social Problems. 14(2):128-47.

Burt, Cyril. 1925. The Young Delinquent. New York: D. Appleton and Company.

Chapple, Constance. 2005. "Self-Control, Peer Relations, and Delinquency." Justice Quarterly 22(1):89-106.

Charmaz, Kathy. 2006. Constructing Grounded Theory: A Practical Guide through Qualitative Analysis. London: Sage Publications.

Cohen, Lawrence E. and Marcus Felson. 1979. "Social Change and Crime Rate Trends: a Routine Activity Approach." American Sociological Review 44(4):588-608.

Costello, Barbara. 2010."Peer Influence Toward Conformity." Journal of Crime and Justice 33(1):97-116.

Costello, Barbara J. and Trina L. Hope. 2016. Peer Pressure, Peer Prevention: The Role of Friends in Crime and Conformity. New York: Routledge.

Fisher, Bonnie S., John J. Sloan, Francis T. Cullen, and Chunmeng Lu. 1998. "Crime in the Ivory Tower: The Level and Sources of Student Victimization." Criminology 36(3): 671-710.

Glueck, Sheldon and Eleanor Glueck. 1950. Unraveling Juvenile Delinquency. Cambridge: Harvard University Press.

Gottfredson, Michael R. and Travis Hirschi. 1990. A General Theory of Crime. Stanford, CA: Stanford University Press.

Haynie, Dana L. 2001. "Delinquent Peers Revisited: Does Network Structure Matter?" American Journal of Sociology 106(4):1013-57. 
Haynie, Dana L and D. Wayne Osgood. 2005. "Reconsidering Peers and Delinquency: How Do Peers Matter?" Social Forces 84(2):1109-30.

Hirschi, Travis. 1969 [2002]. Causes of Delinquency. Berkeley: University of California Press.

Kandel, Denise B. 1978. "Homophily, Selection, and Socialization in Adolescent Friendships." American Journal of Sociology 84(2):427-36.

Kornhauser, Ruth Rosner. 1978. Social Sources of Delinquency: An Appraisal of Analytic Models. Chicago: University of Chicago Press.

Laub, John H. and Robert J. Sampson. 2003. Shared Beginnings, Divergent Lives: Delinquent Boys to Age 70. Cambridge, MA: Harvard University Press.

Matsueda, Ross L., and Kathleen Anderson. 1998. "The Dynamics of Delinquent Peers and Delinquent Behavior." Criminology 36(2):269-308.

McGloin, Jean Marie. 2009. "Delinquency Balance: Revisiting Peer Influence." Criminology 47(2):439-77.

Mercken, Liesbeth, Tom A.B. Snijders, Christian Steglich, Erkki Vartiainen, and Hein De Vries. 2010. "Dynamics of Adolescent Friendship Networks and Smoking Behavior." Social Networks 32(1):72-81.

Osgood, D. Wayne, and Amy L. Anderson. 2004. "Unstructured Socializing and Rates of Delinquency." Criminology 42(3):519-50.

Osgood, D. Wayne, Janet K. Wilson, Jerald G. Bachman, Patrick M. O'Malley and Lloyd D. Johnston. 1996. "Routine Activities and Individual Deviant Behavior." American Sociological Review 61(4):635-55.

Rebellon, Cesar J. 2012. "Differential Association and Substance Use: Assessing the Roles of Discriminant Validity, Socialization, and Selection in Traditional Empirical Tests." European Journal of Criminology 9(1):73-96.

Sampson, Robert J., and John H. Laub. 1993. Crime in the Making: Pathways and Turning Points Through Life. Cambridge, MA: Harvard University Press.

Shaw, Clifford R. 1931. The Natural History of a Delinquent Career. Chicago: University of Chicago Press.

Shaw, Clifford R., and Henry D. McKay. 1942. Juvenile Delinquency and Urban Areas. Chicago: University of Chicago Press. 
Simons-Morton, Bruce, and Rusan S. Chen. 2006. "Over Time Relationships Between Early Adolescent and Peer Substance Use." Addictive Behaviors 31(7): 1211-1223.

Sutherland, Edwin. 1947. Principles of Criminology, Fourth Edition. Philadelphia: Lippincott.

Sutherland, Edwin, Donald R. Cressey, and David F. Luckenbill. 1992. Principles of Criminology, Eleventh Edition. Lanham, MD: General Hall.

Sutherland, Edwin. H. and Cressey, Donald R. 1966 [1934]. Principles of Criminology, Seventh Edition. Philadelphia: Lippencott.

Warr, Mark. 2002. Companions in Crime: The Social Aspects of Criminal Conduct. New York: Cambridge University Press.

Warr, Mark and Mark Stafford. 1991. "The Influence of Delinquent Peers: What They Think or What They Do?" Criminology 29(4):851-66.

Wechsler, Henry, Jae Eun Lee, Meichun Kuo, Mark Seibring, Toben F. Nelson and Hang Lee. 2002. Trends in College Binge Drinking During a Period of Increased Prevention Efforts:

Findings from Four Harvard School of Public Health College Alcohol Study Surveys:

1993-2001, Journal of American College Health, 50:5, 203-217. 


\begin{tabular}{|c|c|c|c|c|c|}
\hline \multicolumn{6}{|c|}{ Table 1. Types of Behavior } \\
\hline \multicolumn{3}{|c|}{ Positive Influence Attempts } & \multicolumn{3}{|c|}{ Negative Influence Attempts } \\
\hline Not drive drunk & $17 \%$ & 22 & Drink alcohol & $26 \%$ & 32 \\
\hline Other & $14 \%$ & 18 & Bad academic behavior (cheat, skip class) & $16 \%$ & 19 \\
\hline Stay in college/go to college & $11 \%$ & 14 & Smoke marijuana & $12 \%$ & 15 \\
\hline Improve health/fitness & $11 \%$ & 14 & Other & $9 \%$ & 11 \\
\hline Not do drugs & $7 \%$ & 9 & Go to party & $8 \%$ & 10 \\
\hline Quit smoking & $5 \%$ & 6 & Dangerous stunts (race cars, jump off cliffs) & $8 \%$ & 10 \\
\hline Apply for programs/Join extracurriculars & $5 \%$ & 6 & Steal/shoplift & $6 \%$ & 7 \\
\hline Not go to a party & $4 \%$ & 5 & Sneak out of house & $5 \%$ & 6 \\
\hline Not to get into a fight & $4 \%$ & 5 & Sneak into movie/concert & $3 \%$ & 4 \\
\hline Health (other): go through surgery & $3 \%$ & 4 & Damage property & $3 \%$ & 4 \\
\hline Not commit suicide & $2 \%$ & 3 & Do something silly/gross & $2 \%$ & 3 \\
\hline Stop hanging out with "bad" crowd & $2 \%$ & 3 & & & \\
\hline Stay at job & $2 \%$ & 3 & & & \\
\hline Improve at sport & $3 \%$ & 4 & & & \\
\hline Cope with loneliness & $2 \%$ & 3 & & & \\
\hline End relationship & $2 \%$ & 3 & & & \\
\hline Turn in lost property & $2 \%$ & 2 & & & \\
\hline Not shoplift & $1 \%$ & 1 & & & \\
\hline Write a note after car accident & $1 \%$ & 1 & & & \\
\hline \multirow[t]{2}{*}{ Seek therapy } & $1 \%$ & 1 & & & \\
\hline & $100 \%$ & 127 & & $100 \%$ & 121 \\
\hline
\end{tabular}


Table 2. Methods of Influence

Positive Influence Attempts

Simple offer/suggest practical solutions

Emphasize costs \&/or benefits

$\begin{array}{rrr}\text { legal/academic/parental } & 10 \% & 19 \\ \text { health } & 8 \% & 15 \\ \text { moral } & 1 \% & 1\end{array}$

Coercion

Talking, not otherwise specified

Encouragement

Sustained visits/interactions

Other/Unclear

Physical intervention

Coaching

Similar experiences

Recruit others to help

Respondent \& influencee will bond

Appeals to friendship

Little cost, nothing to lose

Appeals to empathy

\begin{tabular}{|c|c|}
\hline Percent & Obs. \\
\hline $21 \%$ & 39 \\
\hline $19 \%$ & 35 \\
\hline $10 \%$ & 19 \\
\hline $8 \%$ & 15 \\
\hline $1 \%$ & 1 \\
\hline
\end{tabular}

$11 \% \quad 20$

$9 \% \quad 17$

$7 \% \quad 13$

$6 \% \quad 11$

$4 \% \quad 8$

$4 \% \quad 8$

$4 \% \quad 7$

$3 \% \quad 5$

$2 \% \quad 3$

$2 \% \quad 3$

$1 \% \quad 2$

$1 \% \quad 2$
$8 \% \quad 16$
Negative Influence Attempts

\begin{tabular}{|c|c|c|}
\hline & Percent & Obs. \\
\hline Minimize consequences & $23 \%$ & 36 \\
\hline legal/academic/parental & $16 \%$ & 25 \\
\hline health & $4 \%$ & 7 \\
\hline moral & $3 \%$ & 4 \\
\hline Persistent offers & $17 \%$ & 26 \\
\hline Other/Unclear & $13 \%$ & 21 \\
\hline Coercion & $13 \%$ & 20 \\
\hline Simple offer/suggestion & $13 \%$ & 21 \\
\hline Appeals to fun & $11 \%$ & 17 \\
\hline Talk & $4 \%$ & 6 \\
\hline Appeals to friendship & $3 \%$ & 4 \\
\hline Bargaining/bribes & $3 \%$ & 4 \\
\hline Flattery & $1 \%$ & 1 \\
\hline "You'll do this eventually..." & $1 \%$ & 1 \\
\hline
\end{tabular}




\begin{tabular}{|c|c|c|}
\hline & Percent & Obs. \\
\hline Respondent's own benefit/amusement & $18 \%$ & 28 \\
\hline Other/unclear ${ }^{(v)}$ & $12 \%$ & 19 \\
\hline Respondent wants someone to be deviant with him/her ${ }^{(s)}$ & $11 \%$ & 18 \\
\hline Person will have fun/enjoy it (a) & $11 \%$ & 18 \\
\hline Doing things together/spend time together ${ }^{(v)}$ & $11 \%$ & 17 \\
\hline Wants person to let loose ${ }^{(a)}$ & $10 \%$ & 15 \\
\hline Initiate friend into new thing (a) & $6 \%$ & 9 \\
\hline Create memories/appeals to youth ${ }^{(v)}$ & $4 \%$ & 7 \\
\hline Respondent wants to avoid consequences (legal/academic/parental) & $4 \%$ & 7 \\
\hline Respondent was drunk $^{(n)}$ & $4 \%$ & 6 \\
\hline Didn't have money (a) & $3 \%$ & 4 \\
\hline Meet friends ${ }^{(v)}$ & $2 \%$ & 3 \\
\hline Impress friends ${ }^{(\mathrm{s})}$ & $2 \%$ & 3 \\
\hline Bored ${ }^{(\mathrm{s})}$ & $2 \%$ & 3 \\
\hline
\end{tabular}

Superscripts refer to whether a motivation is selfish (s), altruistic (a), neither (n), or varies (v). 
Table 4. Motivations for Positive Influence

Physical consequences/health ${ }^{\text {(a) }}$

Other/unclear ${ }^{(\mathrm{v})}$

Consequences/Benefits (legal/academic/parental) ${ }^{\text {(a) }}$

Empathy ${ }^{(a)}$

Doesn't want person to be unhappy or afraid ${ }^{\text {(a) }}$

Morality ${ }^{(v)}$

Protective role (a)

See person happy ${ }^{\text {(a) }}$

Empathy for third party ${ }^{(a)}$

Feel action is gross ${ }^{(v)}$

Felt sorry ${ }^{(a)}$

\begin{tabular}{cc} 
Percent & Obs. \\
\hline $27 \%$ & 46 \\
$14 \%$ & 23 \\
$11 \%$ & 19 \\
$10 \%$ & 17 \\
$8 \%$ & 14 \\
$8 \%$ & 14 \\
$8 \%$ & 13 \\
$5 \%$ & 8 \\
$4 \%$ & 6 \\
$2 \%$ & 4 \\
$2 \%$ & 3 \\
$1 \%$ & 2 \\
\hline $100 \%$ & 169
\end{tabular}

Superscripts refer to whether a motivation is selfish (s), altruistic (a), neither (n), or varies (v). 
Table 5. Direction of Motivations for Each Reported Motive

\begin{tabular}{cccccccc} 
& \multicolumn{2}{c}{ Altruistic } & \multicolumn{2}{c}{ Selfish } & Neither & $N$ \\
\cline { 2 - 8 } Positive Influence Attempt & $83 \%$ & 134 & $12 \%$ & 19 & $6 \%$ & 9 & 162 \\
& & & & & & & \\
Negative Influence Attempt & $36 \%$ & 52 & $53 \%$ & 76 & $10 \%$ & 15 & 143 \\
\hline
\end{tabular}


Table 6. Direction of Motivations for Each Influence Attempt

\begin{tabular}{cccccccccccccc}
\hline & Altruistic & Selfish & Neither & Altruistic \& Neither & Selfish \& Neither & Selfish \& Altruistic & $\boldsymbol{N}$ \\
\cline { 2 - 10 } Positive Influence Attempt & $74 \%$ & 75 & $4 \%$ & 4 & $6 \%$ & 6 & $5 \%$ & 5 & $0 \%$ & 0 & $12 \%$ & 12 & $\mathbf{1 0 2}$ \\
& & & & & & & & & & & \\
Negative Influence Attempt & $23 \%$ & 22 & $45 \%$ & 43 & $9 \%$ & 9 & $6 \%$ & 6 & $6 \%$ & 6 & $10 \%$ & 10 & $\mathbf{9 6}$ \\
\hline
\end{tabular}

